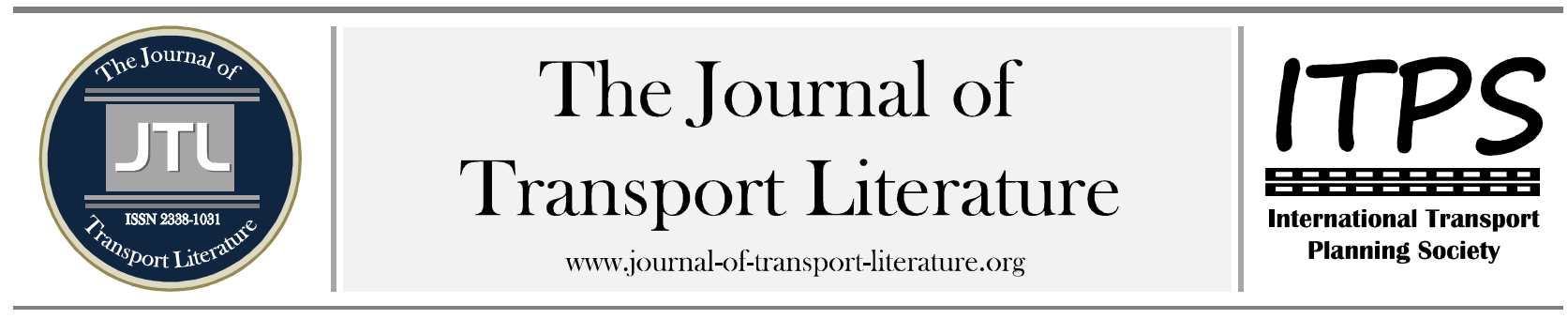

\title{
Identificação de fatores para a efetivação da descentralização de voos internacionais regulares de passageiros no Brasil
}

Rodrigo Rosa da Silva Cruvinel+; José Augusto Abreu Sá Fortes

University of Brasília, Brasília, Brazil

\section{Article Info}

Palavras-chave: transporte aéreo internacional análise hierárquica de processos identificação de fatores

Submitted 1 Nov 2013; received in revised form 8 Jan 2014; received 27 Jul 2014

Licensed under

Creative Common

CC-BY 3.0 BR

\section{Resumo}

0 trabalho visa identificar elementos que influenciam o transporte aéreo internacional brasileiro, de forma a estimular que haja a descentralização de voos internacionais regulares de passageiros no Brasil. Foram realizadas pesquisas junto a passageiros dentro de salões de embarque internacionais, e a utilização da técnica de análise multicritérios AHP junto a docentes e a profissionais dos setores público e privado que atuam com transporte aéreo no Brasil. Encontrou-se que, para os passageiros, o fator primordial é o menor tempo total de viagem e que as agências de viagens ainda exercem uma forte influência sobre estes quando da compra da passagem aérea. Já para os profissionais, o fator chave é a existência de elementos que incentivem a demanda em uma dada região, e que os estímulos governamentais, como subvenções econômicas e revisões de Acordos de Serviços Aéreos (ASAs), possuem indicativos que são pouco efetivos para o setor no Brasil.

+ Corresponding author. Universidade de Brasília, Faculdade de Tecnologia - Programa de Pós-Graduação em Transportes. Anexo SG-12, 1o Andar. Asa Norte. 70910-900 Brasilia - DF. Brasil.

E-mail address: rodrigorosacruvinel@gmail.com.

\section{Introdução}

O trabalho visa auxiliar na identificação da priorização dos elementos que devem ser trabalhados no desenvolvimento de políticas públicas de estímulo à aviação internacional no Brasil, especialmente no que toca as ações governamentais para o setor. Para tanto, buscou-se identificar e elencar, em ordem de importância, os fatores que influenciam na descentralização de voos internacionais regulares de passageiros do Brasil para aeroportos fora das cidades do Rio de Janeiro e de Guarulhos, pois há uma excessiva concentração nos aeroportos destas cidades, que respondem por aproximadamente $80 \%$ do fluxo de passageiros internacionais do país.

Foi considerado que a flexibilização de Acordos de Serviços Aéreos (ASAs) era um fator estruturante para estimular a descentralização do setor, pois alguns ASAs firmados pelo Brasil estão próximo do seu limite técnico e/ou estão passando por revisões, como o assinado com a Argentina, que atingiu o limite de frequências semanais acordadas entre os dois países, e o assinado com os EUA, que passou em 2011 por modificações visando a sua ampliação e flexibilização.

Em uma operação comercial aeroportuária diversos atores compartilham uma infraestrutura escassa, o aeroporto, cuja utilização para voos internacionais demanda elevados investimentos de todos os entes. Quanto à identificação dos elementos preponderantes para a operação aeroportuária, a concorrência entre aeroportos e a consequente atração de usuários e operadoras aéreas, há ampla literatura internacional que trata deste assunto, porém com foco na identificação de fatores que influenciam a escolha de um aeroporto por operadores e usuários quando em uma região com múltiplos aeroportos, como os trabalhos de Blackstone et al (2006), Maertens (2010), Lian e Rønnevik (2011), Redondi et al (2011) e Murça e Correia (2013).

Diante de tais premissas, o presente estudo foca no mercado brasileiro, no qual visa identificar qualitativamente os elementos que afetam particularmente o país, atentando-se para as distintas visões de passageiros e de profissionais da academia, governo e entidades de classe que atuam no segmento. Para tanto, foi utilizado durante a pesquisa a Análise Hierárquica de Processos - AHP.

Como resultado da pesquisa realizada junto aos passageiros foi encontrado que o elemento mais prezado para estes ao realizar um voo internacional é o menor tempo despendido em uma viagem. E como principal resultado da pesquisa AHP, foi encontrado que a existência de demanda, representada por um elevado PIB e existência de polo industrial em uma determinada região, são preponderantes para que haja a descentralização de voos internacionais no Brasil.

Dessa forma, o artigo possui a seguinte estrutura: na Sessão 1 é apresentado um breve histórico das políticas regulatórias que afetaram o transporte aéreo internacional; na Sessão 2 é apresentado o levantamento bibliográfico, em que são identificados os elementos relevantes para a operação de voos internacionais, atentando-se às questões infraestruturais, operacionais das companhias aéreas e políticas governamentais; na Sessão 3 são apresentadas as opiniões de passageiros quando dentro dos saguões de embarque internacional dos aeroportos de Guarulhos e de Brasília, com o intuito de 
identificar os elementos que influenciam a atração de voos internacionais; na Sessão 4 é utilizado o método de Análise Hierárquica de Processos (AHP); na Sessão 5 é explicitado os resultados da aplicação do método AHP junto a profissionais que atuam na academia, na iniciativa privada e em órgãos governamentais, de forma a identificar a ordem de importância dos elementos elencados. Por fim, têm-se as conclusões do estudo.

\section{A regulação e liberalização da aviação civil}

Os voos internacionais possuem como base o Acordo de Serviços Aéreos (ASAs), um instrumento jurídico internacional que pode ser assinado de forma bilateral, entre dois países, ou multilateral, entre vários países, e que determinariam as condições técnicas e comerciais dos voos que podem ser realizados entre os países signatários. Este instrumento jurídico é utilizado, desde a sua instituição, como instrumentos de proteção econômica do setor aéreo de cada nação. Nele, inúmeras restrições foram impostas para evitar que medidas antieconômicas fossem adotadas em seus Estados por terceiros países, enfraquecendo as companhias aéreas de cada país (Fay, 2002).

O setor aéreo permaneceu fortemente regulamentado em nível global desde meados da década de 1940 até o final dos anos de 1970. Em 1978, os Estados Unidos promoveram a liberalização do seu mercado aéreo com a vigência do Airline Deregulation Act (Ferreira et al, 2008). A liberalização do mercado aéreo global atingiu um novo patamar em 1992, quando os Estados Unidos fizeram um acordo com a Holanda para ampliar o ASA que regulamentava o transporte aéreo entre estes países. 0 acordo firmado posteriormente passou a ser chamado de Acordo de Céus Abertos por conta das suas características mais flexíveis, praticamente sem restrições governamentais para as operações aéreas (Vieira, 2012).

Destaca-se que, segundo Intervistas-Ga2 (2009), as liberalizações dos mercados de transportes aéreos geraram impactos positivos na economia dos países, não apenas aumentando o tráfego aéreo. Um estudo sobre a liberalização do acesso ao mercado aéreo internacional expôs que: i) foram criadas novas rotas e aumentou a competitividade entre as companhias no mercado aéreo, na União Europeia; ii) as tarifas foram reduzidas e o tráfego aumentou, havendo um decréscimo das tarifas de viagens a lazer de $17 \%$ e aumento no tráfego de $108 \%$ após a liberalização bilateral entre a Índia e o Reino Unido (CAA, 2006, apud Intervistas-Ga2, 2009); iii) houve um crescimento de 38\% na quantidade de empregos gerados na aviação, no turismo e em outras indústrias (CAA, 2004, apud Intervistas-Ga2, 2009).

Diante de tais premissas e visando ampliar a liberalização do setor aéreo internacional, o Brasil alterou vários ASAs para a modalidade céus abertos, de forma a estimular a diversificação de rotas e ligações, e a entrada de novas companhias no tráfego aéreo internacional brasileiro. Mais de 20 acordos com alguns dos principais mercados brasileiros foram firmados, como com os Estados Unidos, que a partir de 2015 passará a ser da modalidade céus abertos, com o intuito de estimular a descentralização de voos internacionais no Brasil (Fonte: Correio Brasiliense, 2011, "Saiba como passageiros podem se beneficiar dos acordos de céus abertos", obtido em www.correiobraziliense.com.br).

\section{Fatores de influência para a escolha de aeroportos para a realização de voos internacionais regulares de passageiros}

Além da flexibilização de acordos de serviços aéreos, buscou-se identificar outros elementos importantes para estimular a descentralização de voos internacionais no Brasil. Em pesquisa bibliográfica, identificou-se que dentre alguns fatores que influenciam a percepção dos usuários dos terminais aeroportuários, tanto passageiros quanto operadores aéreos, em relação ao conforto e nível de serviço são a existência de sala de embarque adequada para a realização do check-in e a disponibilização de serviços de conveniência (Fiorio e Correia, 2007).

A forma como a malha aérea doméstica está estruturada é outro elemento que afeta a disposição da malha aérea internacional, sobretudo pela facilidade de conectividade com outras localidades no país, pois influenciam na escolha de um aeroporto, dentre outros fatores, a sua posição geográfica favorável, de forma a facilitar o acesso de diversas regiões em menor tempo total de viagem possível (Martín e Roman, 2004; Redondi et al, 2011). Ademais, a existência de hubs aéreos estimulam a atração de investimentos e o desenvolvimento econômico em uma dada região (Bel e Fageda, 2008; StraussKahn e Vives, 2009; Sismandou et al, 2013).

Bennot et al (2012) expõe que parcerias entre empresas aéreas nacionais e ou internacionais atuam de forma a propiciar a alimentação dos voos de forma a atingir a maximização dos seus lucros. As ações podem se dar por meio da participação de alianças empresariais, como a Star Aliance e a Oneworld, e/ou por meio da realização de codeshares entre as transportadoras aéreas. Essas parcerias beneficiam as companhias aéreas propiciando economia de escalas, favorecendo os consumidores, tendo em vista maior capilaridade da malha aérea, e elementos de conforto e conveniência, como salas Vips, integração de programas de milhagem, entre outros benefícios.

A ausência do fornecimento adequado de serviços aeroportuários para a prestação do transporte aéreo afeta de maneira importante a implantação e manutenção de voos internacionais. Exemplo de tal cenário é a empresa aérea portuguesa TAP que, após mais de dois anos de voos regulares, em 2012 cancelou de maneira temporária os seus serviços no aeroporto de Viracopos (Campinas/SP) tendo como uma das alegações a ausência de empresa de catering adequado no aeroporto, para o fornecimento de refeições a bordo. A ausência de um free shop na instalação aeroportuária foi outro argumento levantado, já que, segundo a TAP, levava muitos viajantes a preterirem o aeroporto por não poderem comprar itens com isenção de impostos (Fonte: O Estado de São Paulo, 2012, "Viracopos Deixa de Ter Voos Internacionais", obtido em www.estadao.com.br). Ademais, estudo de Suzuki et al (2003) demonstrou que os passageiros aéreos consideram se o aeroporto dispõe de facilidades, como a existência de restaurantes e áreas de estacionamentos, quando do momento da escolha do aeroporto em que realização as suas viagens.

Em um estudo na região da Philadelphia, Estados Unidos, realizado por Blackstone et al. (2006), foi identificado que o preço das passagens foi levado em consideração pelos passageiros quando da escolha de um aeroporto, porém tal fator não possuía grande importância. Os principais elementos considerados pelos passageiros foram a disponibilização de voos diretos, disponibilização de amplo estacionamento, o tempo de espera para a realização do check-in, renda dos passageiros e a distância de casa. Fatores estes que se relacionam com o tempo de viagem.

Maertens (2010) fez um estudo de como promover a descentralização de voos internacionais na Europa. Ao analisar o mercado europeu, foi identificado que a maior parte dos voos de longa distância se concentravam em aeroportos hubs, e 
que os aeroportos secundários tinham dificuldades em conseguir atrair voos. A pesquisa indicou que para conseguir atrair voos o aeroporto deveria estar localizado em uma região com renda mais elevada e que, existindo tal fator, passa a ser elemento condicionante a disponibilização de pista adequada para receber aeronaves de maior porte. No entanto, tal condição se demonstrava economicamente inviável em razão da baixa utilização da pista por aeronaves de maior porte.

Há casos de ações governamentais que foram promovidas de forma a estimular a criação de voos em um dado aeroporto (Fonte: Europa. Commission decision of 12 February 2004 concerning advantages granted by the Walloon region and Brussels South Charleroi Airport to the airline Ryanair in connection with its establishment at Charleroi. Official Journal of European Union, l. 137/1, 30/04/2004), como a ação belga em fornecer incentivo econômico-financeiro para que a Ryanair instalasse a sua base operacional em Charleroi, ou mesmo estímulos à captação de voos e promoção de turismo, como o promovido pelo Programa Decola Minas, do Governo do Estado de Minas Gerais.

\section{Opiniões de passageiros para a escolha de aeroportos internacionais}

Diante das questões apresentadas, buscou-se compreender os motivos que influenciam os passageiros na escolha de um determinado aeroporto brasileiro para a realização de viagens internacionais. Para tanto, foram entrevistados passageiros dentro das salas de embarque internacional dos aeroportos de Guarulhos (GRU) e de Brasília (BSB). O primeiro por ser a principal porta de entrada/saída por via aérea brasileira, e o segundo em razão de ter apresentado um vigoroso crescimento no número de voos internacionais nos últimos anos, por ter uma posição geográfica favorável e ter uma importante atuação como centro de distribuição de passageiros em voos domésticos.

Visando um intervalo de confiança de $95 \%$ e margem de erro de 5\%, foram entrevistados 385 passageiros. Foram aplicados 278 questionários em Guarulhos, entre os dias 30/06/2012 e 01/07/2012, e 107 questionários em Brasília, entre os dias 07/07/2012 e 08/07/2012. A análise dos resultados encontrados na pesquisa foi realizada de forma descritiva e qualitativa, com o intuito de identificar os percentuais de respostas encontrados em cada item.

Das perguntas realizadas, duas correspondiam o cerne do trabalho. A primeira questão, "Qual(is) o(s) motivo(s) que levou(aram) o(a) senhor(a) a escolher este aeroporto para deixar o Brasil?", explicitou que os quatro itens mais importantes para os passageiros de ambos os aeroportos são: i) de mais fácil acesso, mais próximo de casa/trabalho (GRU: 29,7\%; BSB: 42,1\%); ii) outros (GRU: 15\%; BSB: 19\%); iii) determinação da empresa aérea (GRU: 13,1\%; BSB: 11,6\%); e iv) agência de viagens determinou (10,5\%; BSB: 8,3\%).

A segunda questão, "Quais são as opções disponibilizadas em um aeroporto que levam o(a) senhor(a) a escolhê-lo para realizar as suas viagens internacionais a partir dele?", no qual cada passageiros podia dar até três respostas, explicitou que os pontos mais importantes para os passageiros eram: i) facilidade de acesso ao aeroporto (GRU: 65,1\%; BSB: 67,3\%); ii) agilidade dos trâmites burocráticos de alfândega/imigração (GRU: 46\%; BSB: 29\%); iii) ter voos de conexão para o meu destino final (GRU: 45\%; BSB: 48,6\%); iv) preços das passagens serem mais baratas (GRU: 41,4\%; BSB: 38,3\%); v) ter empresa aérea que ofereça programa de milhagem (GRU: 24,5\%; BSB: 21,5\%); vi) qualidade de atendimento e ampla variedade de itens do free-shop (GRU: 17,3\%; BSB: 17,8\%); vii) outros (GRU: 34,9\%; BSB: 28,1\%).

Observando os resultados encontrados, o menor tempo de viagem necessário para os deslocamentos apresentou-se como fundamental para os entrevistados. Cenário que corrobora pesquisa realizada por Blackstone et al. (2006), cujos passageiros locais também demonstraram menor sensibilidade a variação de custos ante ao menor tempo despendido em viagem. Destaca-se que trabalhos de Hess e Polak (2005), Hess e Polak (2006) e Ishii et al (2009) também encontraram que o tempo total de viagem é um fator importante quando da escolha de um sítio aeroportuário pelos passageiros.

Destacaram-se na pesquisa os itens agilidade dos trâmites burocráticos e existência de programas de milhagem, sendo este o último item confirmador de pesquisas anteriores que expuseram que programas de milhagem servem como elemento de atração dos passageiros (Cairns e Galbraith, 1990; Proussaloglou e Koppelman, 1995; Proussaloglou e Koppelman, 1999).

\section{Estruturação do método de análise}

Para o desenvolvimento do trabalho foi escolhida a técnica Análise Hierárquica de Processos (AHP), por ser um dos métodos de tomada de decisão mais utilizados mundialmente (sendo largamente utilizado pela academia e grandes empresas) e se adequar ao objetivo proposto no trabalho (identificar os fatores que afetam a descentralização de voos internacionais).

\subsection{Descrição do método de trabalho}

Os questionários utilizados para a aplicação da técnica foram montados tendo como base os fatores destacados por passageiros de voos internacionais que partem do Brasil e em pesquisa bibliográfica. Dentre os elementos levantados, estes foram classificados, de maneira arbitrária, em cinco grupos: Demanda; Estímulos Governamentais; Infraestrutura Aeroportuária - Lado Ar; Terminal de Passageiros - Lado Terra; e Facilidade de Acesso ao Aeroporto.

Destes, o subgrupo Demanda foi composto por: i) elevada densidade populacional; ii) elevado PIB local iii) facilidades de parcerias comerciais (codeshare/milhagens); (iv) menor tempo total de viagens, e; v) ter polo industrial nas imediações.

O subgrupo Infraestrutura Aeroportuária - Lado Ar foi composto por: i) aeroporto com ociosidade em sua capacidade operacional; ii) ampla rede local de fornecedores; iii) baixos custos de operação do aeroporto; iv) capacidade de pátios e pistas; v) existência de pontes de embarque.

O subgrupo Terminal de Passageiros - Lado Terra foi composto por: i) ampla área disponível para embarque e desembarque; ii) amplo estacionamento; iii) estrutura adequada da alfândega e da imigração; iv) existência de aeroshopping; v) ter free-shop amplo, variado e com bom atendimento, e; vi) grande número de balcões de check-in.

O subgrupo Facilidade de Acesso ao Aeroporto foi composto por: i) aeroporto ser hub doméstico; ii) aeroporto ter amplo serviço de transporte público.

Por fim, o subgrupo Estímulos Governamentais foi composto por: i) concessão de subvenção econômica; ii) flexibilização de acordos de serviços aéreos; iii) menor incidência de impostos estaduais/locais sobre a cadeia produtiva da aviação; iv) promoção de ações turísticas para captação de voos internacionais, e; v) restrição ao uso de aeroportos centrais. 
Para validar a escolha dos fatores escolhidos, foi desenvolvido um questionário que foi submetido a profissionais que desempenham suas funções na ANAC; na Coordenação de Transportes e Logística da Secretaria de Acompanhamento Econômico do Ministério da Fazenda (SEAE/MF); na Infraero no Aeroporto de Fortaleza; e uma discente do curso de mestrado em Engenharia de Infraestrutura Aeronáutica do Instituto Tecnológico de Aeronáutica (ITA).

Para responder o questionário foram escolhidos profissionais que atuam em órgãos e entidades do poder público federal e da iniciativa privada que possuem envolvimento direto com a aviação civil de passageiros no Brasil (Secretaria de Acompanhamento Econômico do Ministério da Fazenda, Agência Nacional de Aviação Civil, Infraero, Embratur, Sindicato Nacional das Empresas Aeroviárias (SNEA), Associação Internacional de Transporte Aéreo (IATA Brasil) e Confederação Nacional dos Transportes (CNT)), e de docentes universitários que atuam como pesquisadores no referido setor (2 do ITA e 2 da Universidade de Brasília (UnB)). Destaca-se que as respostas obtidas na pesquisa refletem apenas a opinião pessoal dos profissionais que trabalham nos órgãos citados, não refletindo, em nenhuma hipótese, a posição oficial dos órgãos e entidades em que os entrevistados trabalham.

\section{Análise dos resultados encontrados ao aplicar o método AHP}

A análise do método AHP consiste na hierarquização dos critérios e subcritérios estudados de forma a identificar a ordem de importância que melhor atenderia aos anseios de todos os grupos ao serem analisados de maneira conjunta.

Ao analisar as respostas dadas pelos diferentes atores trabalhados de maneira conjunta, pode-se identificar que o item "Demanda" sobressaiu-se em relação aos demais itens analisados, representando o principal elemento necessário para que se obtenha a descentralização de voos internacionais no Brasil, com 0,492 pontos do peso entre todas as opções analisadas. Para o atingimento do objetivo em questão, o segundo item a ser trabalhado em ações públicas é a disponibilização da "Infraestrutura Aeroportuária (Lado Ar)" adequada para a operação das aeronaves, com 0,168 pontos do peso total das respostas obtidas. Em terceira, quarta e quinta colocações, respectivamente, estão as opções "Terminal de Passageiros (Lado Terra)" (0,141), "Disponibilização de Estímulos Governamentais" $(0,102)$ e "Facilidade de Acesso ao Aeroporto" $(0,097)$. 0 nível de inconsistência obtido foi de 0,00235 , abaixo limite máximo de 0,1 considerado aceitável pelo método AHP (Expert Choice, 2002). Abaixo está disposto a ordem hierárquica dos subcritérios considerados quando analisados conjuntamente as respostas dadas pelos grupos entrevistados.

Tabela 1 - Ordem hierárquica de preferência dos subcritérios analisados (fonte: autores)

\begin{tabular}{|c|c|c|}
\hline 1ㅇ - Elevado PIB local; & $9^{\circ}$ - Baixos custos operacionais & $17^{\circ}$ - Ter amplo serviço de transporte público \\
\hline $2^{\circ}$ - Ter polo industrial nas imediações & $\begin{array}{l}10^{\circ}-\text { Restrição ao uso de aeroportos } \\
\text { centrais }\end{array}$ & $\begin{array}{l}18^{\circ} \text { - Redução de impostos estaduais / } \\
\text { municipais sobre a aviação }\end{array}$ \\
\hline $3^{\circ}$ - Elevada densidade populacional & $11^{\circ}$ - Aeroporto ser hub doméstico & $\begin{array}{l}19^{\circ} \text { - Flexibilização de acordos de serviços } \\
\text { aéreos }\end{array}$ \\
\hline $4^{\circ}$ - Capacidade de pistas e pátios & $\begin{array}{l}12^{\circ} \text { - Parcerias comerciais (codeshares, } \\
\text { programas de milhagem) }\end{array}$ & $20^{\circ}$ - Existência de pontes de embarque \\
\hline $\begin{array}{l}5^{\circ} \text { - Estrutura adequada de alfândega } \\
\text { e imigração }\end{array}$ & $\begin{array}{l}13^{\circ}-\text { Existência de ociosidade } \\
\text { operacional }\end{array}$ & $21^{\circ}-$ Ter amplc \\
\hline $\begin{array}{l}6^{\circ} \text { - Ampla área disponível para } \\
\text { embarque e desembarque }\end{array}$ & $\begin{array}{l}14^{\circ} \text { - Aç̃óes turísticas para captação de } \\
\text { voos internacionais }\end{array}$ & $22^{\circ}$ - Concessão de subvenção econômica \\
\hline $\begin{array}{l}7^{0} \text { - Grande número de balcões de } \\
\text { check-in }\end{array}$ & $\begin{array}{l}15^{\circ}-\text { Ter free-shop variado, amplo e } \\
\text { com bom atendimento }\end{array}$ & $23^{\circ}$ - Ampla rede local de fornecedores \\
\hline $8^{\circ}-$ Menor tempo total de viagem & $16^{\circ}$ - Fácil acessibilidade viária & $24^{\circ}$ - Existência de aeroshopping \\
\hline
\end{tabular}

\section{Conclusão}

0 presente artigo expõe que não basta a adoção de um regime regulatório mais liberal para que se consiga a descentralização dos voos internacionais. Segundo opiniões de passageiros internacionais, dentre os diversos elementos que podem contribuir para que haja a atração de passageiros internacionais para um determinado aeroporto brasileiro, $o$ menor tempo de viagem necessário para os deslocamentos apresentou-se como fundamental, representado pela opção de fácil acesso aos aeroportos. Tendo este ponto atendido, os demais pré-requisitos são relegados pelos passageiros, acarretando na determinação do aeroporto a ser utilizados pela operadora aérea e pelo agente de viagens. Quanto aos resultados encontrados com a pesquisa AHP, apesar da disparidade das linhas de pensamento entre os atores ouvidos, os grupos ouvidos chegaram a uma conclusão unânime: para que se tenha a descentralização de voos internacionais, o elemento mais importante que deve existir é a demanda.

Ao observar os subcritérios considerados como principais para os atores entrevistados, tem-se que estes são básicos para a aviação civil: condicionantes de demanda e de infraestrutura aeroportuária. 0 fato destes terem aparecido melhor colocados, pode indicar que a satisfação de tais premissas básicas pode não estar sendo devidamente oferecidas ao setor no Brasil, levando a flexibilização de acordos de serviços aéreos, item que tem a possibilidade de ampliar o fluxo de voos, ser preterida ante outros elementos.

Além disso, encontrou-se que a subvenção econômica, elemento que foi utilizado para conduzir o processo de estímulo à capilarização de voos internacionais na Bélgica, apresenta fortes indicativos que é de difícil aceitação entre os profissionais do setor aéreo brasileiro. Explicação de tal posicionamento pode advir do forte viés político que eleva o risco do Estado privilegiar determinados grupos econômicos, podendo gerar, insegurança política, econômica e regulatória.

Ao comparar os dados obtidos com a realização da pesquisa AHP com o elemento "menor tempo total de viagem", declarado como mais importante pelos passageiros, tem-se que o menor tempo total de viagem apenas não está entre os 10 subcritérios mais importantes para os profissionais que atuam na iniciativa privada. Resultado que indica um descasamento entre as ideias dos fornecedores e dos consumidores do serviço de transporte aéreo internacional.

Estudos futuros podem aprofundar a presente pesquisa, de forma a explicar, de maneira pormenorizada, as razões que levaram os itens considerados como mais importantes a terem recebido tais colocações. Ação que pode vir a gerar o desenvolvimento de uma função utilidade, no qual pesos são dados a cada elemento em uma fórmula, tornando-se um instrumento a ser utilizado por interessados na identificação dos elementos prioritários em cada região para a atração de voos internacionais de passageiros. 


\section{References}

Bel, G., \& Fageda, X. (2008). Getting there fast: globalization, intercontinental flights and location of headquarters. Journal of Economic Geography, 8, 471-495.

Bennot W., Brueckner J. K., \& Proost S. (2012). Intercontinental Airport Competition. Discussion Paper Series, 12.03. Environmental \& Transport Economics, Faculty of Business and Economics, Katholieke Universiteit Leuven.

Blackstone, E. A., Buck, A. J., \& Hakin, S. (2006). Determinant of airport choice in a multi-airport region. Atlantic Ec. Journal, 34, $313-326$.

Cairns, R. D., \& Galbraith, J. W. (1990). Artificial compatibility, barriers to entry and frequent-flyer programs. Canad. J. Econ., $23(4)$, $807-816$.

Expert Choice. (2002) Expert Choice for groups. Help Topics. Expert Choice Inc.

Fay, C. M. (2002) Crises na aviação brasileira: a ordem internacional e as questões internas. Indic. Econômico, FEE, 30(1), $124-136$.

Ferreira, N. S., Barragan, G. A., \& Lima, M. G. (2008). A experiência internacional na desregulação econômica do transporte aéreo. Journal of Transport Literature, 2(1), 61-124.

Fiorio, T. A., \& Correia, A. R. (2007). Uma medida do nível de serviço oferecido em terminais de passageiros em aeroportos. 13o Encontro de Iniciação Científica e Pós-Graduação do ITA - XIII ENCITA.

Hess, S., \& Polak, J. W. (2005). Mixed logit modelling of airport choice in multi-airport regions. J. Air Transport Management, 11(2), 59-68.

Hess, S., \& Polak, J. W. (2006). Exploring the potential for cross-nesting structures in airport choice analysis: a case-study of the great London area. Tranportation Research Part E: Logistics and Transportation Review, 42(2), 63-81.

Ishii, J., Sunyoung, J., \& Van Dender, K. (2009). Air travel choices in multi-airport markets. Journal of Urban Economics, 65(2), $216-227$.

Intervistas-Ga2. (2009). Impact of Liberalisation on Selected Countries. Obtido em issuu.com.

Lian, J. I., \& Rønnevik, J. (2011). Airport competition - regional airports losing ground to main airports. Journal of Transport Geography, $19(1), 85-92$.

Maertens, S. (2010). Drivers of long haul flight supply at secondary airports in Europe. Journal of Air Transport Management, 16, $239-243$.

Martín, J. C., \& Román, C. (2004). Analyzing competition for hub location in intercontinental aviation markets. Transportation Research Part E, 40(2), 135-150.

Murça, M. C. R., \& Correia, A. R. (2013). Análise da modelagem da escolha aeroportuária em regiões de múltiplos aeroportos. Journal of Transport Literature, 7(4), 130-146.

Proussaloglou, K., \& Koppelman, F. (1995). Air carrier demand an analysis of market share determinants. Transportation, 22(4), 371-388.

Proussaloglou, K., \& Koppelman, F. (1999). The choice of air carrier, flight, and fare class. J. Air Transport Management, 5(4), $193-201$.

Redondi, R., Malighetti, P., \& Paleari, S. (2011). Hub competition and travel times in the world-wide airport network. Journal of Transport Geography, 19(6), 1260-1271.

Sismanidou, A., Tarradellas, J., Bel, G., \& Fageda, X. (2013). Estimating potential long-haul air passenger traffic in national networks containing two or more dominant cities. Journal of Transport Geography, 26, 108-116.

Strauss-Kahn, V., \& Vives, X. (2009). Why and where do headquarters move? Regional Science and Urban Economics, 39(2), $168-186$.

Suzuki, Y., Crum, M. e Audino, M. (2003). Airport choice, leakage and experience in single-airports regions. Journal of Transportation Engineering, 129(2), 212-218.

Vieira, B. C. (2012). Acordo de céus abertos entre EUA e União Europeia: uma visão geral. Journal of Transport Literature, 6(1), 200-220.

\section{Abstract}

The paper aims to identify which elements influence the Brazilian international air transport, in order to stimulate that there is decentralization of scheduled international passenger flights in Brazil. It was applied a surveys for passengers inside international boarding lounges, and used a multi-criteria analysis AHP with professors and professionals from the public and private sectors who work with air transportation in Brazil. As the view of the international passengers, they care mainly with the factor lowest total travel time when choosing the airport to make their travel, and they plan their trip under strong influence of travels agency. For professionals whose works in the international airline industry, the existence of elements that stimulate demand in some geographical area is the key factor to create news internationals flights. Furthermore, it was found that government stimuli, as economic subsidies and review Air Services Agreements (ASAs), have little effectiveness to create new international flights in Brazil.

Key words: international air transport; analytic hierarchy process; identification of factors; passengers. 